\title{
BEHAVIORAL COMPONENTS IN RELATIONSHIPS OF ECONOMIC AGENTS (EXAMPLE OF THE UKRAINIAN CAR MARKET)
}

\author{
Glib Mazhara ${ }^{1}$ \\ SkyDoor13@gmail.com \\ Volodymyr Kapustian \\ ${ }^{1}$ Department Mathematical modeling of economic systems \\ National Technical University of Ukraine «Kyiv Polytechnic Institute Igor Sikorsky» \\ 37 Peremohy ave., Kyiv, Ukraine, 03056
}

\begin{abstract}
In neoclassical economics a concept of individual is seen as a logical thinking machine, which accurately analyzes all information received and, based on it, makes decisions that maximize his/her personal gain and minimize risks while achieving his/her goals. Such behavior of a person is called rational. Such concept serves as a source of neoclassicism for the construction of supply and demand models, operation of tax systems, business cycles, inflation etc.

It was not accepted to pay attention to the psychology of decision-making, it was believed, that these transient, random factors pale against the grandeur of economic incentives. Psychologists are interested in solutions that are emotional, casual, pursued by some sort of cultural ideas, norms, rules, and may even be phobias, conversely economics is the science of rational behavior.

The purpose of this paper is to identify and analyze the behavioral components and their influence on the interaction of economic agents in the commodity market. The study used methods of constructing a multivariate regression model, OLS, Student and Fisher criteria, statistical research, sociological surveys and expert opinion. Authors will analyze the behavioral aspects of market relationships on the example of used car market in Ukraine

This paper provides several different situations and tested them with real market data to demonstrate that both buyers and sellers may not act rationally on the market, set prices, based on their personal beliefs, subjective and psychological factors and that must be considered when building economical models.
\end{abstract}

Keywords: behavioral economics, classical theories, models of multivariate regression.

DOI: $10.21303 / 2504-5571.2020 .001184$

\section{Introduction}

For a long time, economists have all been dealing with a neoclassical mainstream economy that studies rational behavior. Within this model, a person (more precisely, he/she will be called an economic person) is a rational mechanism. It is guided only by its beliefs and has the usual framework on which (and taking into account available information) to make decisions. Such a person is convenient to use in modeling: he/she makes a logical and flawless choice and has a significant amount of insight.

Behavioral economic originates from the second part of $20^{\text {th }}$ century, the evidences of a better use of the behavioral approach than a classic economical models were formed in different branches such as firm [1], bank sector, monetary [2], investment [3], for the decision making process $[4,5]$.

Car market is also very popular type of a market for different economists to work with because of the reasons, mentioned below. There are several authors, trying to analyze the problem with this approach, some of them do it from the seller's approach [6], or even analyze the entire brunch [7] and also point on "brand" [8]. Sometimes authors step up from the classical approach to the behavioral one, but it is not widely described [9]. Sometimes authors are not interested in reasons, but just analyzing the data [10]; it has several weak points, first of all it is hard to understand what exactly leads to an increase or decrease of purchase. $2^{\text {nd }}$, if the market is stable and grows so it will grow, same for decreasing, you even can model the floating market, but without understanding the behavior, you will never predict an enormous situation such as crisis, or stagnations etc. Still 
all of these authors were trying to build logical models and find a logical component into buyers' behavior. And also, none of them was analyzing the non-verbal "communication" between seller's and consumer's behavior, which is the purpose of this paper.

But in the real life of a person there are emotions, feelings, instincts, mistakes. Therefore, a person can act differently from the classic modeling, nonstandardly, that is - irrationally. Thus, it can be concluded, that the psychological component is essential in person's decision making.

A new branch of economic science, behavioral economics, is attempting to link the two sciences, as well as to extend the boundaries of the traditional rational subject's behavior.

Based on different sources, authors can define the behavioral economy. It is an area of economic theory that explicitly considers the psychological features of human perception, judgment, and action in order to study and understand the economic decision-making processes of consumers, borrowers, and investors.

The purpose of this paper is to identify and analyze the behavioral components and their influence on the interaction of economic agents in the car market.

\section{Materials and Methods}

The study used methods of constructing a multivariate regression model, OLS, Student and Fisher criteria, statistical research, sociological surveys and expert opinion.

Authors will analyze the behavioral aspects of market relationships on the example of used car market in Ukraine. The market for used cars is selected due to a number of factors:

- The market has no barriers to entry - all sales are made through online car placement sites. More than 90 percent of the market selling used cars in Ukraine is on the same internet site - auto.ria. com. Similarly, the German market is located on two equal sites mobile.de and auto.de. This factor eliminates the lack of information from buyers or the asymmetry of information between buyers.

- The used car market itself is a demonstration of the human behavior, because their motivat tion is quite straightforward - a buyer tries to buy a product he/she is looking for that meets his/her criteria, and a seller tries to sells his/her product and both of them have a direct relationship with each other. If, for example, to take the market of new cars, then the motivation of a seller is more complicated - there is a factory that manufactured the goods, which will be bought by a dealer under any conditions, a dealer tries to sell his/her goods, but not directly, but through dependent sellers with a bonus or salary, and they use price and non-price advantages of the sale, etc. That is why the used car market is a pure buyer-seller interaction system.

Each car has a manufacturer - a brand that makes a car, such as Mercedes or Peugeot and has a model, for example, Mercedes may have "S-class" and Peugeot - "RCZ". The authors can distinguish objective price factors and subjective ones for each product and car. Objective factors include: year of manufacture (how old a car is at the moment), what mileage of the car, engine power, automatic transmission, packages of the car. On the other hand, there are so many subjective factors, known only to the seller. For example, the real condition of the car, whether the repair was carried out, what is the quality of such repair, additional equipment for the car, the mode of operation and more.

\section{Experimental procedures}

1. 1. Objective and subjective price criteria

Let's start with an analysis of the Ukrainian used car market, and let's take Peugeot RCZ as an example. To do this, the authors take all the objective metrics and price for this model from the portal auto.ria.com. The authors build a multiple regression model, using the least squares method. To do this, the authors will use the free Gretl app. The results are shown in Fig. 1.

19 observations were selected, the main results of the modeling R-square 0.41, Fisher 2.42, at Fisher's tabular value of 3.11. Though, the determination of this model is low, and our chosen objective factors, as regressors, do not explain the price of this product.

Let's look at another model from another price segment - a luxury brand, a car of another type - Lexus RC.

Consider the detailed data for modeling in Table 1. And the results are shown in Fig. 2. 


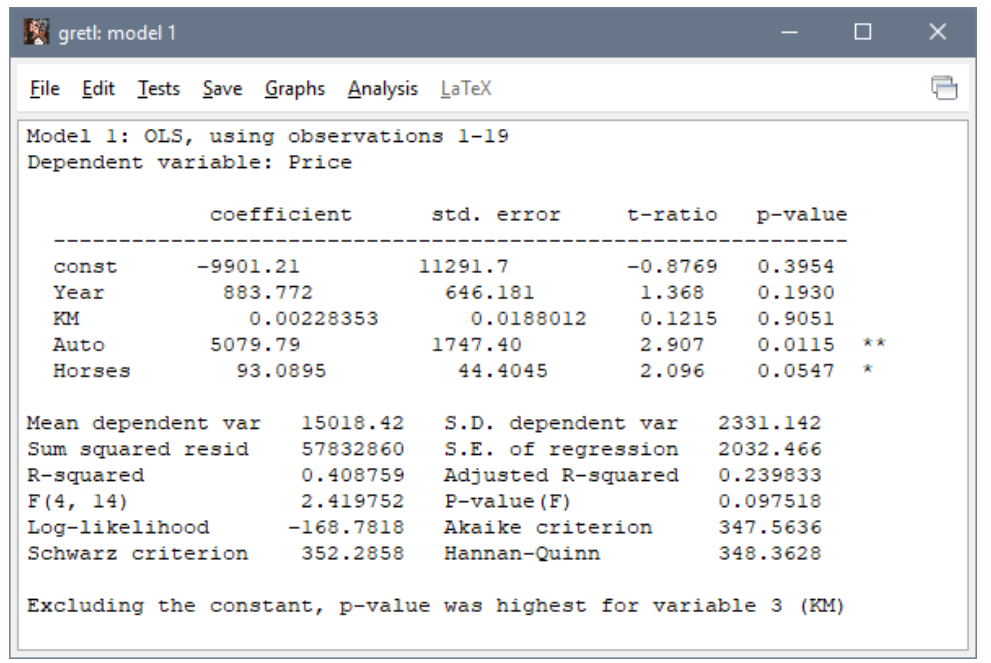

Fig. 1. Results of the Peugeot model. Source: Author's own development

Table 1

Elements of the system for modeling

\begin{tabular}{ccccc}
\hline Years & Mileage, th. Km. & Automatic gearbox & Engine, h.p. & Price, $\$$ \\
\hline 3 & 57 & 1 & 250 & 26500 \\
3 & 48 & 1 & 250 & 28999 \\
4 & 83 & 1 & 314 & 29999 \\
3 & 18 & 1 & 250 & 29999 \\
3 & 31 & 1 & 250 & 30000 \\
3 & 31 & 1 & 250 & 31777 \\
3 & 77 & 1 & 250 & 31900 \\
3 & 28 & 1 & 250 & 32000 \\
2 & 9 & 1 & 250 & 35000 \\
2 & 24 & 1 & 250 & 41000 \\
2 & 10 & 1 & 250 & 45000 \\
2 & 10 & 1 & 250 & 48000
\end{tabular}

Source: Author's own development

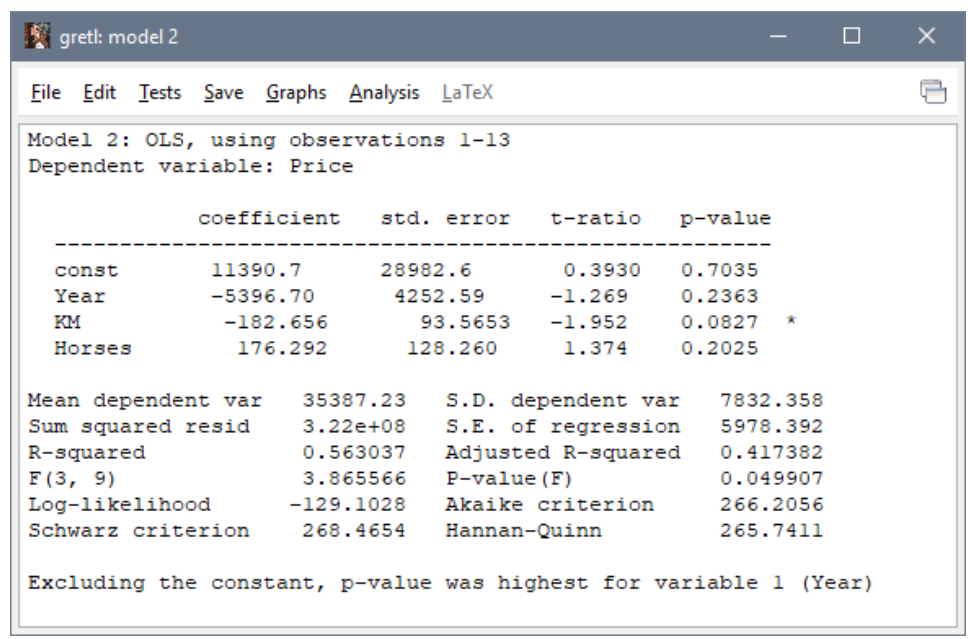

Fig. 2. Lexus model results. Source: Author's own development 
13 observations were selected, the main results of the modeling R-square 0.56, Fisher 3.86, at Fisher's tabular value of 3.86. Though, the determination of this model is low, and our chosen objective factors, as regressors, do not explain the price of this product.

Other models from different brands, in several price segments, and types have provided similar results. The conclusion is that, even in the context of one model, prices are formed not by objective factors, but by subjective and behavioral factors. The same conclusion was reached by mobile.de [11]. The developers of the portal decided to add a "rating of attractiveness of a specific product (car)", but formed it not on absolute values, but on relative ones. If we take a look at Table 1, we will see that all cars had 3 years of operation, 250 horsepower, the presence of an automatic gearbox, but different prices - the portal automatically generates a price rating for such vehicles by several criteria. In other words, the price rating is not objective, because they are the same, const., but rather subjective. This indicates that in their everyday life, people have long used the behavioral component to explain such phenomena as, for example, pricing.

So, let's move on from objective to subjective and psychological factors.

\section{2. New approach for the "lemon market"}

One of the first who noticed the behavioral aspects such as subjective factors of market relations in the market of used cars was George Akerlof, who in 1970 wrote an article, entitled "The market for "lemons": quality uncertainty and the market mechanism" [7].

The main content of the work can be formulated as follows: "If buyers do not have the information about the quality of goods to the same extent as sellers, bad products are displacing good ones until the market disappears." The used car market is an illustration of this problem: "lemons" in American slang are called cars with defects, found only after purchase.

As the true technical condition of a used car is much better known to a seller than to a buyer, when buying a car it is impossible to predict in advance whether the car will be "good" or "bad". Therefore, the buyer expects a car of some weighted average quality and is ready to pay for it some weighted average price. Thus, the seller of a good, well-groomed car cannot get a fair (full) price for his/her car and is forced to leave the market. As sellers of "good" machines leaves the market, the average price that a buyer is willing to pay for a car of unknown quality, decreases all the way down to the complete disappearance of "good" cars for sale.

"It should be emphasized that the choice (of such an example) is dictated by considerations rather of greater concreteness and a better understanding of the problem than the importance or reality of the situation under consideration.” J. Akerloff [12].

Almost 50 years ago, the author could not have guessed that Ukraine would become a country, where this situation would be realistic, important and would be able to clearly demonstrate this example, moreover, it would become a problem of "stagnation" of the market as a whole.

So, in Ukraine, we have a market where we sell cars, but we do not have a market for "purchase requests", that is, the system is such that supply exceeds demand, but until recently, according to the classical theory, the market could balance itself. So, what has changed?

Consider 2014. To begin with, prices in Ukraine for used cars are on average higher than European ones. There are three main reasons for this: political, legal and economic barriers. In 2015, Law 3251 was introduced to reduce excise duty rates on used vehicles. Thus, one of the barriers to price differentiation in the markets of Europe, America and Ukraine was removed. This caused a boom in cars from the US and Europe. Though, the demand has increased, but the supply has increased multiply to the demand growth. There is nothing extraordinary as of now, since prices would be reduced over time. Let us take this as an example - right after the introduction of the law, the popular American car Ford Mustang cost \$ 36 thousand, after a few months the supply was so much higher than the demand that the price of the same corresponding car was reduced to $\$ 26$ thousand, which is almost $30 \%$ but this did not solve the problem of "stagnation in the market". After all, the reason is also in psychological factors. In Ukraine, most cars were in "good" condition, so the price, set by a seller, often coincided with what a buyer imagined. But cars from America are almost entirely composed of "a car after an accident", that is "bad" condition. Consider the example of the BMW M4 2016 - average price in the Ukrainian market - $\$ 70$ thousand (cars of Ukrainian origin), and cars of American ori- 
gin $-\$ 50$ thousand (30\% lower). Let's discuss one of the psychological aspects of pricing. A number of sellers from different groups and buyers were interviewed and their opinions were as follows:

A seller of the car of Ukrainian origin - I bought a car for \$ 100 thousand, the average rate of decline for the year around $10 \%$ - I sell my car for \$ 70 thousand as three-year old car in "good" condition.

Sellers of cars of the American origin are divided into two types of sellers. The first type frankly says that the car is in "bad" condition, so its price is $\$ 50$ thousand, but $1^{\text {st }}$ type is rarer (explanation below). The second type of them subjectively believes that his/her car is not worse than the "good" condition, since it has same specs and then the price should not be different and sells it for slightly less money than the car in "good" condition, but not nearly close to its true value as "bad" condition car.

A buyer, as noted above, wants to buy a car and spend an average amount of money. Initially, he/she was ready to spend $\$ 70,000$, but now there are cars for $\$ 50,000$ on the market, so he/she is ready to spend only $\$ 60,000$, so he/she is no longer "able" to buy a car of "good" condition because the price is higher than his/her expectations. He/she can buy a car for $\$ 50000$, but he/she does not want to buy it because it is a "bad" state (as he/she was told), so he/she is likely to buy a car for 60000 thousand dollars of the same "bad" state, but where it is hidden. In the next phase, a seller of a car of "good" condition leaves the market because he/she does not want to lower the price, because it is objective, and has no chance to sell his/her car. A "honest" car seller of "bad" condition also has no desire to continue his/her previous strategy, because it loses to the strategy of "not fair" and artificially raises the price. A buyer, on the contrary, still hopes to buy a car of "average" quality, but his/her imaginary price has decreased even more, because sellers of cars of "good" condition (with a higher price) have not remained on the market. Therefore, a buyer wants to buy a car even cheaper and of "average" quality, and such cars are no longer on the market.

\section{Results}

- A "good" car seller cannot sell a car at the point of objective price and does not intend to reduce it objectively.

- A buyer is not willing to buy anything because he/she wants it cheaper and is not satisfied with car’s quality.

- A seller of a bad condition car does not reduce the price, the prices are artificially inflated, the seller tries to hide the shortcomings and issue the car for the "good" condition car for its price.

The authors can say this: the situation of "stagnation in the market" was caused by objective and subjective factors, but its resolution depends only on the psychological and behavioral aspects of buyers and sellers.

Consider resale value. The resale value is the amount that is expected to be obtained from the sale at some point in the future. This factor is influenced by a large number of objective factors, from a mathematical point of view the resale value can be calculated by the following formula:

$$
V(t)=V_{0} \exp ^{-r t}
$$

And it has a graph of the following form at $r=0.2$, Fig. 3 .

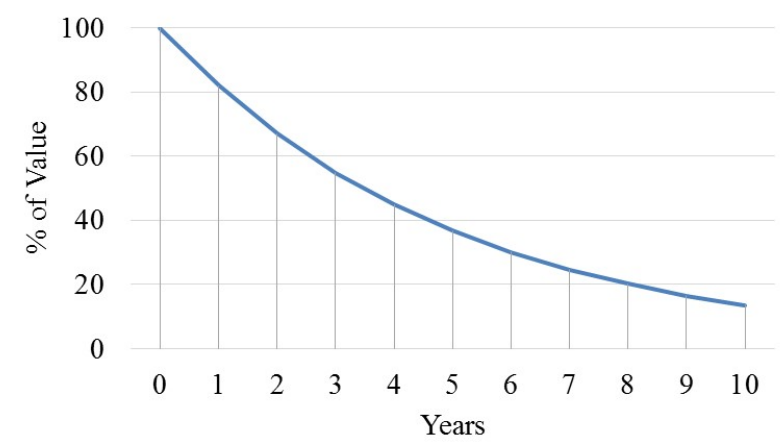

Fig. 3. General view of the residual value curve. Source: Author's own development 
$\mathrm{V}(\mathrm{t})$ - resale value after $\mathrm{t}$ years, exp - Exponential, $\mathrm{r}$ - depreciation rate per year. But indicator $r$ is subjective and different for each company and model. For example, among luxury cars $r$ is the lowest at Porsche [13], and among the mass class at Toyota [13]. Consider the case of Porsche - the company makes some of the best sports cars in the world [14], an extremely old company with a rich history, not once won the races but so did Jaguar and Lotus, to which all these characteristics belong. However, the Porsche coefficient $r$ is much smaller than that of Jaguar or Lotus. So, the Jaguar F-type in the German market mobile.de lost almost $20 \%$ of its value in 1 year (50 thousand euros instead of 62 thousand euros.). And Porsche 911 lost $14 \%$ of the value (90 thousand euros instead of 104 thousand euros.). This is due to the subjective attitude of people to a particular brand or model, by the way, it also depends on the market country. So, there will be another difference in the Ukrainian market. Jaguar F-type on the Ukrainian market auto. ria.com [15] lost almost $45 \%$ of its value in 3 years (54 thousand euros instead of 100 thousand euros), and Porsche 911 lost $30 \%$ of its value (102 thousand euros instead of 134 thousand euros). The authors model the resale value on these two models, using the formula, and compare them to actual market prices. The authors will write the results in Table 2.

Table 2

Car depreciation over the years in different markets

\begin{tabular}{ccc}
\hline Country & Jaguar F type & Porsche 911 \\
\hline Germany 1 y.o. & $20 \%$ & $14 \%$ \\
Modeled Germany 3 y.o. & $45 \%$ & $35 \%$ \\
Germany 3 y.o. & $45 \%$ & $35 \%$ \\
Ukraine 3 y.o. & $45 \%$ & $30 \%$
\end{tabular}

Source: Author's own development

As can be seen from the table, $1^{\text {st }}$, if the coefficient $r$ is known, then it is possible to accurately calculate the resale value after a few years (for example the case of Germany). Secondly, resale value may vary depending on the market, which is again driven by the subjective attitude and psychological beliefs of the people, regarding the particular brand and model. Of course, it can be said, that $5 \%$ is not a big difference, but in absolute terms it is about 156 thousand UAH, more than 3 years working for the minimum wage in Ukraine, and it is driven by the attitude and psychological beliefs.

\section{Conclusions}

In traditional economics it was not accepted to pay attention to the psychology of decision-making, it was believed that these transient, random factors pale against the grandeur of economic incentives. Psychologists are interested in solutions that are emotional, casual, pursued by some sort of cultural ideas, norms, rules, and may even be phobias, and economics is the science of rational behavior.

In this paper the authors have analyzed and have described the reasons of stagnations of the Ukrainian car market, with the behavioral approach and proposed the behavioral solution to this problem. The authors have analyzed objective and subjective factors for pricing on the market, and suggested using comparing method, similar to one, used at mobile.de [11] biggest auto market in EU. We also considered the re-sale value model as one of the combined methods for pricing on the market. The future research must be concentrated on systematization of the behavioral approach and its usage in different markets and spheres, since as of now each of them needs to be considered separately, and has its own behavioral components and it is extremely time consuming without systematization methods.

The paper provided several different situations and tested them with real market data to demonstrate that both buyers and sellers may not act rationally on the market, set prices, based on their personal beliefs, subjective and psychological factors and that must be considered when building economical models. Two cases in the paper were mentioned. The first one shows that the same 
model of a car with similar parameters may vary in prices, and there are no objective reasons for that. The second one shows that even the resale value formula has a subjective multiplier $r$, which is different not only by models or manufacturer, but even by region of the market.

The reasons for the "stagnation" of the car market of Ukraine were identified, and pointed as more psychological than pure economical. The principles of resale value formation and the influence of emotional and psychological factors were formed.

\section{References}

[1] Cyert, R. M., March, J. G. (1962). A Behavioral Theory of the Firm. Englewood Cliffs: Prentice Hall, 167.

[2] McClure, S., Laibson, D., Loewenstein, G., Cohen, J. (2004). Separate Neural Systems Value Immediate and Delayed Monetary Rewards. Science, 306 (5695), 503-507. doi: http://doi.org/10.1126/science.1100907

[3] Graham, B. (2009). The Intelligent Investor. Moscow: House «Williams», 38.

[4] Thaler, R. (1981). Some empirical evidence on dynamic inconsistency. Economics Letters, 8 (3), 201-207. doi: http:// doi.org/10.1016/0165-1765(81)90067-7

[5] O’Donoghue, T., Rabin, M.; Elster, J. (Ed.) (1999). Addiction and Self- Control. Addiction: Entries and Exits, Russell Sage Foundation.

[6] Tomyuk O (2015). Analysis of methods of determination of product competitiveness of automotive enterprises. Scientific Bulletin of Kherson State University, 10 (4).

[7] A study of consumer perception of car market \& buying behavior (2010). Available at: https://www.slideshare.net/ hemanthcrpatna/a-study-of-consumer-perception-of-car-market-buying-behavior

[8] Consumer Buying Behavior in Automobile Industry. Available at: https://www.academia.edu/7318995/Consumer_Buying_ Behavior_in_Automobile_Industry

[9] Moscati, I. (2013). From classical political economy to behavioral economics. EGEA spa, 279.

[10] H“ulsmann, M., Borscheid, D., Friedrich, C. M., Reith, D. (2012). General Sales Forecast Models for AutomobileMarkets and their Analysis. Transactions on Machine Learningand Data Mining, 5 (2), 65-86.

[11] Germany's largest vehicle market online. Available at: https://promo.mobile.de/sites/preisbewertung/?lang=en

[12] Akerlof, G. A. (1970). The Market for "Lemons": Quality Uncertainty and the Market Mechanism. The Quarterly Journal of Economics, 84 (3), 488-500. doi: http://doi.org/10.2307/1879431

[13] 2020 Best Resale Value Brand: Subaru (2020). Available at: https://www.kbb.com/new-cars/best-resale-value-awards/ best-brand

[14] Top 10 best sports cars 2020 (2020). Available at: https:/www.autocar.co.uk/car-news/best-cars/top-10-best-sports-cars

[15] Auto.ria. Available at: https://auto.ria.com

Received date 06.02.2020

Accepted date 10.03.2020

Published date 31.03.2020
(C) The Author(s) 2019

This is an open access article under the CC BY license (http://creativecommons.org/licenses/by/4.0). 